\title{
Experimental research and mathematical modelling of soil and groundwater contamination with nitrogen compounds
}

\author{
A. M. Marinov \& M. A. Diminescu \\ Department of Hydraulics, \\ Hydraulic Machinery and Environmental Engineering, \\ Faculty of Power Engineering, Polytechnic University, \\ Bucharest, Romania
}

\begin{abstract}
We propose here a project to study the complex phenomenon of groundwater pollution with nitrogen compounds. It is an attempt to answer the following basic questions: having found the quantity of rain or irrigation, and the quantity of fertilizer, how much will these damage the layer of drinkable water? Which is the best solution to minimize the damage? Our proposal is based on our earlier work, which treated the fluid flow through the first layer of unsaturated soil. Our main goal is to extend the model to include what happens in soil lower levels and how the influence of groundwater hydrodynamics can be taken into account. The nitrogen compound transformations take a key role in our study, which is multidisciplinary (fluid mechanics, chemistry, agriculture studies engineering). The soil pollution study implies the computation of the pollutant concentration through the soil profile. The mathematical models achieve the integration of equations describing the water movement and the pollutant concentrations. We have calibrated the hydraulic model using experimental data.

Keywords: groundwater, pollution, unsaturated soil, nitrogen, nitrate, pollutant concentration, pressure head, mathematical model, coupled model.
\end{abstract}

\section{Introduction}

Groundwater systems are in continuous dynamic interaction at local, intermediate, and regional scales with the surface water systems through the 
unsaturated soil. The degree of the interaction between groundwater, unsaturated soil and surface water (lakes, rivers, and runoff) depends on physiographic and climatic conditions. An understanding of the basic principles of the interactions is therefore useful for an effective management of water resources. With the growing demand for the sustainable management and utilization of natural resources, a better understanding of all aquatic system's components such as the linkage between groundwater and unsaturated soil, becomes imperative.

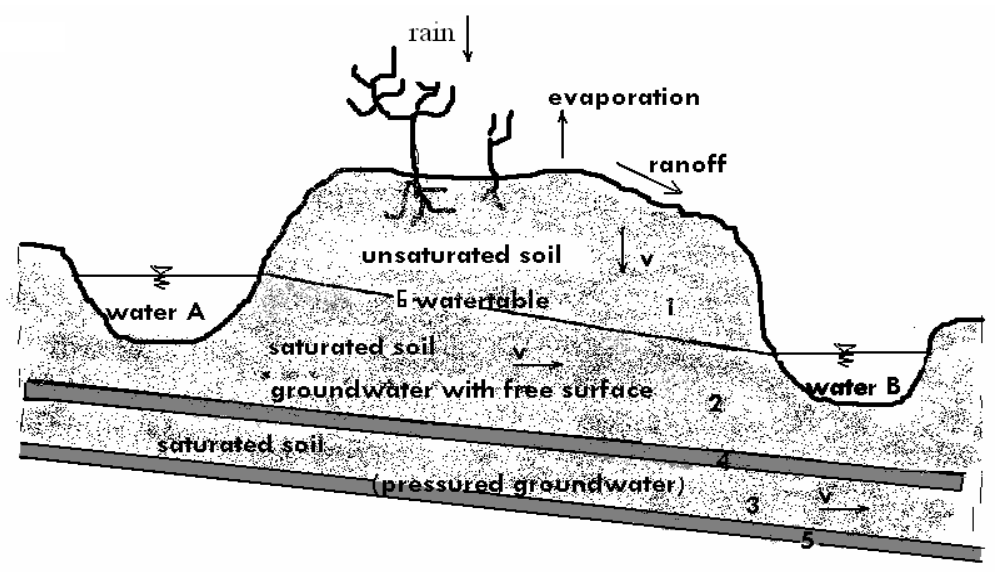

Figure 1: $\quad$ System profile.

Fig. 1 shows a general system whose components are: the surface unsaturated soil (1), the unconfined aquifer (saturated soil) (2) bounded by the watertable (6) and an impermeable layer (4), and the confined aquifer (3) bounded by two impermeable layers.

The rain enters unsaturated soil layer carrying the pollutants toward the groundwater. This process is very complex, depending on the soil moisture retention characteristic, vegetation type, rain, temperature, soil matrix chemical components and pollution sources.

Some of the major pollution problems are caused by nitrogen compounds. Groundwater contaminated with dissolved nitrogen in the form of nitratenitrogen $\left(\mathrm{N}_{-} \mathrm{NO}_{3}{ }^{-}\right)$is a common world-wide concern. Nitrogen in the soil primarily originates from inorganic and organic fertilizers, organic matter, precipitation, and irrigation water. Another pollution source, the septic tanks effluents contain high levels of ammonia-nitrogen and organic-nitrogen. As the effluent infiltrates the soil, much of the ammonia is oxidized to nitrate, which is highly soluble and can percolate through the unsaturated soil, toward the groundwater.

The pollution mechanism of natural water by nitrogen compounds is governed by three distinct types of processes: hydrodynamic mass transport, transformation by biological and chemical reactions, and mass transfer at interface surfaces. The main bio-chemical processes occurring are: mineralization and immobilization of nitrogen and denitrification, related to (partial) anaerobiosis and decomposing organic materials. 
These processes take place in two zones, the upper unsaturated zone, and the lower saturated aquifer. The conditions in the upper, unsaturated zone are strongly determined by infiltration and also by the soil moisture distribution. Soil moisture conditions determine the aeration in the unsaturated zone, and this is directly related to the mineralization of organic nitrogen as well as to the denitrification rate. Many models have been developed to simulate nitrogen behavior in the soil, ranging from scientific research tools to simple management models

\section{Mathematical modelling of nitrogen compounds transport in an unsaturated soil}

The nitrification-denitrification processes, usually presented in literature as successive reactions of first order kinetics, are affected by: dissolved oxygen, micro-organisms, temperature, $\mathrm{pH}$ and carbon content.

In our work we have used the basic diagram of the nitrogen simplified cycle, fig. 2, recommended by Geng [1].

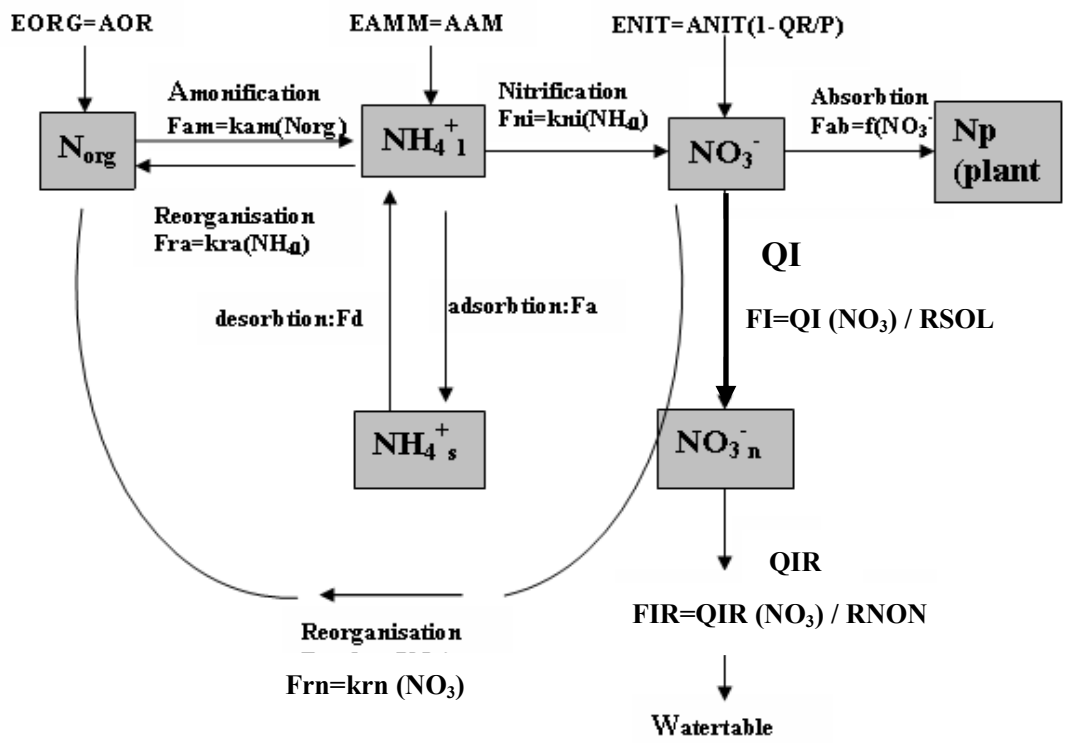

Figure 2: $\quad$ Basis diagram of the Nitrogen Cycle studied by Geng [1].

We compute the concentration of each constituent $\mathrm{NO}_{3}{ }^{-}, \mathrm{NH}_{4}{ }^{+}$, Norg, in the roots' region and $\mathrm{NO}_{3 \mathrm{n}}{ }^{-}$in the unsaturated, without roots, region. $\mathrm{NO}_{3 \mathrm{n}}$ is the nitrate concentration that reaches the watertable. $\mathrm{NO}_{3 \mathrm{n}}{ }^{-}$will be the pollutant concentration at the groundwater upper boundary.

The nitrogen concentrations in each component are related with the chemical entrances (fertilizers concentrations: AOR, AAM, ANIT), and with the water dynamic in the soil. The rain or irrigation intensity, $\mathrm{P}(\mathrm{cm} / \mathrm{hour})$, the surface 
runoff QR (cm/hour), and the moisture retention characteristic of the soil influence the discharges values QI, QIR, the water content in the unsaturated roots' region RSOL $(\mathrm{cm})$, and the water content in the unsaturated without roots region RNON (cm). The nitrogen concentrations in each component are obtained by eqns. (1)-(6) system integration.

$$
\begin{aligned}
& \frac{\mathrm{d}\left(\mathrm{NO}_{3}^{-}\right)}{\mathrm{dt}}=\mathrm{ENIT}-\mathrm{FI}+\mathrm{Fni}-\mathrm{Frn}-\mathrm{Fab}, \\
& \frac{\mathrm{d}\left(\mathrm{NH}_{41}^{+}\right)}{\mathrm{dt}}=\mathrm{EAMM}+\mathrm{Fam}-\mathrm{Fni}-\mathrm{Fra}+\mathrm{Fd}-\mathrm{Fa}, \\
& \frac{\mathrm{d}\left(\mathrm{NH}_{4 \mathrm{~s}}^{+}\right)}{\mathrm{dt}}=\mathrm{Fa}-\mathrm{Fd}, \\
& \frac{\mathrm{d}\left(\mathrm{NH}_{4}^{+}\right)}{\mathrm{dt}}=\mathrm{EAMM}+\text { Fam }- \text { Fni }- \text { Fra }, \\
& \frac{\mathrm{d}(\text { Norg })}{\mathrm{dt}}=\text { EORG }+ \text { Frn }+ \text { Fra }- \text { Fam }, \\
& \frac{\mathrm{d}\left(\mathrm{NO}_{3 \mathrm{n}}^{-}\right)}{\mathrm{dt}}=\mathrm{FI}-\mathrm{FIR} \text {. }
\end{aligned}
$$

Considering the transfer functions in the chemical reactions, described in fig. 2, Fam, Fni, Fab, Fra, Frn, Fd, Fa, FI, FIR, the system 1, 2, 3, 4, 5, 6 becomes:

$$
\begin{aligned}
& \frac{\mathrm{d}\left(\mathrm{NO}_{3}^{-}\right)}{\mathrm{dt}}=(1-\mathrm{QR} / \mathrm{P}) \mathrm{ANIT}-\left(\mathrm{QI} / \mathrm{RSOL}^{-}\left(\mathrm{NO}_{3}{ }^{-}\right)+\left[\mathrm{k}_{\mathrm{ni}} /\left(1+\mathrm{k}_{\mathrm{d}}\right)\right]\left(\mathrm{NH}_{4}{ }^{+}\right)-\right. \\
& \frac{\mathrm{d}\left(\mathrm{NH}_{4}^{+}\right)}{\mathrm{dt}}=\mathrm{AAM}+\mathrm{k}_{\mathrm{am}}(\mathrm{Norg})-\left[\mathrm{k}_{\mathrm{ni}} /\left(1+\mathrm{k}_{\mathrm{d}}\right)\right]\left(\mathrm{NH}_{4}{ }^{+}\right)-\left[\mathrm{k}_{\mathrm{ra}} /\left(1+\mathrm{k}_{\mathrm{d}}\right)\right]\left(\mathrm{NH}_{4}{ }^{+}\right)-\mathrm{B}\left[\left(\mathrm{NO}_{3}{ }^{-}\right) /\left(\left(\mathrm{NO}_{3}{ }^{-}\right)+\mathrm{k}_{\mathrm{ab}}\right)\right] \mathrm{f}_{\mathrm{pp}}{ }^{\prime}(t / \mathrm{T}) \\
& \frac{\mathrm{d}(\mathrm{Norg})}{\mathrm{dt}}= \mathrm{AOR}+\mathrm{k}_{\mathrm{rn}}\left(\mathrm{NO}_{3}{ }^{-}\right)^{-}+\left[\mathrm{k}_{\mathrm{ra}} /\left(1+\mathrm{k}_{\mathrm{d}}\right)\right]\left(\mathrm{NH}_{4}{ }^{+}\right)-\mathrm{k}_{\mathrm{am}}(\mathrm{Norg}) \\
& \frac{\mathrm{d}\left(\mathrm{NO}_{3 \mathrm{n}}^{-}\right)}{\mathrm{dt}}=(\mathrm{QI} / \mathrm{RSOL})\left(\mathrm{NO}_{3}{ }^{-}\right)-\left(\mathrm{QIR} / \mathrm{RNON}^{-}\right)\left(\mathrm{NO}_{3 \mathrm{n}}{ }^{-}\right)
\end{aligned}
$$

where: $k_{\mathrm{am}}, \mathrm{k}_{\mathrm{ra}}, \mathrm{k}_{\mathrm{n}}, \mathrm{k}_{\mathrm{ad}}, \mathrm{k}_{\mathrm{rn}}$ are the rate values of chemical reactions, obtained by model calibration, ANIT, AAM, AOR are nitrogenous fertilizers $\left(\mathrm{kg} \mathrm{ha}^{-1}\right)$, on the soil surface, ENIT, EAMM, EORG are nitrogenous fertilizers $\left(\mathrm{kg} \mathrm{ha}^{-1}\right)$, entering through the surface in the unsaturated soil, QI $(\mathrm{cm} / \mathrm{h})$ is the entrance discharge through the unit surface, QIR $(\mathrm{cm} / \mathrm{h})$ is the entrance discharge in the unsaturated region without roots, at $z_{1}$ depth, (fig. 3), RSOL (cm) is the water content in the roots region, RNON $(\mathrm{cm})$ is the water content in the unsaturated region, without roots, and RTOT $=\mathrm{RSOL}+\mathrm{RNON}$, is the water content in the unsaturated region.

We propose a mathematical model coupling a hydraulic model to compute QI, QIR, RSOL, RNON, with the chemical model represented by eqns. (7)-(10). 

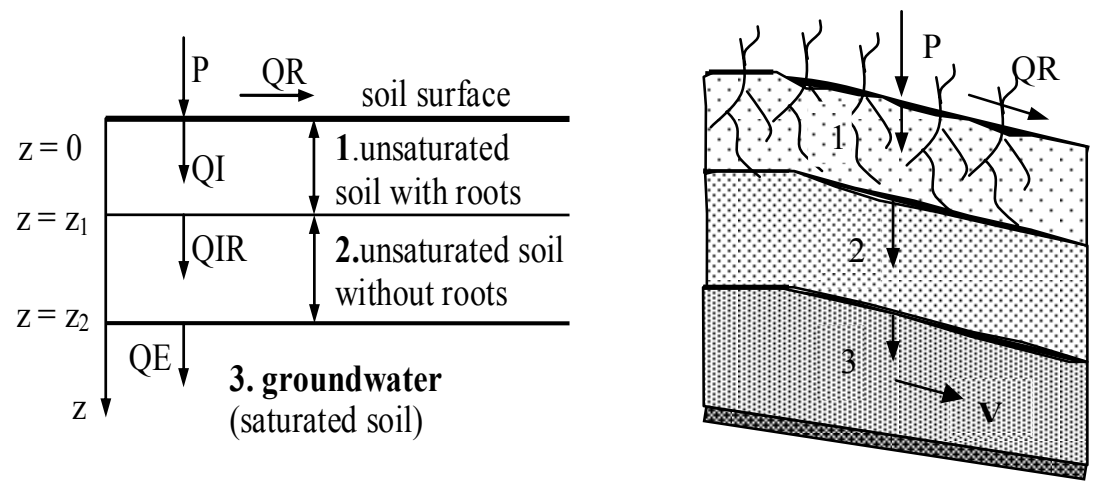

Figure 3: Discharges in the unsaturated-saturated soil profile.

\section{Hydraulic model for the unsaturated soil}

\subsection{Richards' equation}

The transport of $\mathrm{NO}_{3}{ }^{-}$through the unsaturated soil toward the groundwater is related with the water content and it's hydrodynamic. QI, QIR, RSOL, RNON, $\mathrm{P}$, previously defined, are very important hydraulic quantities which influence the nitrogen cycle. Each of them can be computed using the volumetric water content $\theta\left[\mathrm{L}^{3} \mathrm{~L}^{-3}\right]$ and the soil water pressure head $h[\mathrm{~L}]$ variation in time and space.

Usually a model to describe an isothermal one-dimensional fluid flow in the unsaturated porous soil can be obtained by combining the mass conservation equation with the generalized Darcy's law, and is known as Richards' equation:

$$
\frac{\mathrm{d} \theta}{\mathrm{d} h} \frac{\partial h}{\partial t}=\frac{\partial}{\partial \mathrm{z}}\left[K(h)\left(\frac{\partial h}{\partial z}-1\right)\right],
$$

where: $\theta(z, t)\left[\mathrm{L}^{3} \mathrm{~L}^{-3}\right]$ is the volumetric water content, $h(z, t)[\mathrm{L}]$ is the soil water pressure head, $K(h)\left[\mathrm{L} \mathrm{T}^{-1}\right]$ is the hydraulic conductivity, $z[\mathrm{~L}]$ is soil depth taken positive downwards, and $t[\mathrm{~T}]$ is time. We neglected the soil hydraulic functions' hysteresis and the effect of the air phase on water flow. Defining the specific soil water capacity:

$$
\frac{\mathrm{d} \theta}{\mathrm{d} h}=C(h)
$$

Richards' eqn. (11) can be written:

$$
C(h) \frac{\partial h}{\partial t}=\frac{\partial}{\partial z}\left[K(h)\left(\frac{\partial h}{\partial z}-1\right)\right],
$$

where $C(h)$ and $K(h)$ are functions of the local soil water pressure head, $h(z, t)$, at a given moment.

We solved numerically Richards' equation, using a fully implicit finite differences scheme. Vauclin [2] recommended it like stable and convergent and 
demonstrated the best agreement with some leaching experiment and with Philip's semi-analytical solution. [2]

The initial condition for eqn (11) may be any arbitrary function $h(z, 0)=h i(z)$. The upper boundary conditions can be described as a known $q_{0}(t)$ [ $\left.\mathrm{LT}^{-1}\right]$ water flux density (Darcian flux) through the soil surface (precipitation, snowmelt, evaporation):

$$
q(0, t)=\left(-K \frac{\partial h}{\partial z}+K\right)_{z=0, t}=q_{0}(t)
$$

or as a given pressure head, during ponding:

$$
h(0, t)=h_{0}(t) \geq 0 \text {. }
$$

Three conditions can be imposed at the lower boundary $(z=L)$ : a known net fluid flux density

$$
q_{L}(t)=\left(-K \frac{\partial h}{\partial z}+K\right)_{z=L, t}=q_{L}(t),
$$

the pressure head $h(L, t)=h_{L}(t)$, when a water table is present, or a gradient of pressure head $\frac{\partial h}{\partial z}=0$, for a free-draining soil profile.

\subsection{Hydraulic model application}

Our purpose is to predict the hydraulic regime in an unsaturated soil profile, divided in two layers like in fig. 3. The water discharges through a unit surface, at different levels, previously defined, can be computed, using the pressure head values $h(z, t)$ and hydraulic conductivity $K(z, t)$, with the relations (17)-(21).

$$
\begin{aligned}
\mathrm{QI}(t) & =q(0, t)=q_{0}(t) \\
\mathrm{QI}(t) & =\left(-K \frac{\partial h}{\partial z}+K\right)_{z=0, t} \\
\mathrm{QIR}(t) & =\left(-K \frac{\partial h}{\partial z}+K\right)_{z=z_{1}, t} \\
\mathrm{QE}(t) & =\left(-K \frac{\partial h}{\partial z}+K\right)_{z=z_{2}, t} \\
\mathrm{QR}(t) & =\mathrm{P}(t)-\mathrm{QI}(t)
\end{aligned}
$$

A fully implicit finite differences scheme is used to integrate eqn. (13):

$$
C_{i}^{j-1} \frac{h_{i}^{j}-h_{i}^{j-1}}{\Delta t}=\frac{1}{\Delta z}\left[K_{i+\frac{1}{2}}^{j-1}\left(\frac{h_{i+1}^{j}-h_{i}^{j}}{\Delta \mathrm{z}}-1\right)-K_{i-\frac{1}{2}}^{j-1}\left(\frac{h_{i}^{j}-h_{i-1}^{j}}{\Delta \mathrm{z}}-1\right)\right]
$$

with $K_{i+\frac{1}{2}}^{j-1}=\sqrt{K_{i}^{j-1} K_{i+1}^{j-1}}$ and $K_{i-\frac{1}{2}}^{j-1}=\sqrt{K_{i-1}^{j-1} K_{i}^{j-1}} . h(z, t)=h(i, j)=h_{i}^{j}$, are unknown, and the values at the previous time, $(j-1)$, 
$h(z, t-\Delta t)=h(i, j-1)=h_{i}^{j-1}, K(z, t-\Delta t)=K_{i}^{j-1}, C(z, t-\Delta t)=C_{i}^{j-1} \quad$ are given. For a spatial grid $\left(d z=z_{2} /(N-1), i=1\right.$ for $z=0$ and $i=N$ for $\left.z=z_{2}\right)$, eqn.(22) can be writen for $i=2$, to $i=N-1$. For $i=1$ and $i=N$, the boundary conditions are used. Each time step, $j$, we get a tridiagonal linear system of $N$ equations. By solving it, the unknowns $h(i, j), i \in \overline{1, N}$ are found.

$\theta(z, t), K(z, t)$ can be computed using the pressure head values and eqns. (25), (27)), the discharges QI, QIR, QE, QR, with eqns. (17)-(21), the water content in the roots region, RSOL, and the water content in the unsaturated region, without roots, RNON with (23) end (24):

$$
\begin{aligned}
& \operatorname{RSOL}(t)=\int_{\mathrm{z}=0}^{z=z_{1}} \theta(z, t) \mathrm{d} z \\
& \operatorname{RNON}(t)=\int_{\mathrm{z}=z_{1}}^{z=z_{2}} \theta(z, t) \mathrm{d} z
\end{aligned}
$$

\subsection{Estimating the hydraulic model parameters}

Model calibration was performed using measured data in an agricultural field with a known irrigation system. For the soil hydraulic properties we used the Van Genuchten's models [3]. The empirical constants determining the shape of the functions were estimated using experimental pedological data.

The reduced water content in soil, $S_{e}$, can be expressed as:

$$
S_{e}=\frac{\theta-\theta_{r}}{\theta_{s}-\theta_{r}}=\frac{1}{\left[1+(\alpha a b s(h))^{n}\right]^{m}}, \text { for } h<0, \text { or } S_{e}=1 \text {, for } h \geq 0,
$$

where $\theta\left[\mathrm{L}^{3} / \mathrm{L}^{3}\right]$ is the soil water content, depending on the pressure head value, $h[\mathrm{~L}], \theta_{r}\left[\mathrm{~L}^{3} / \mathrm{L}^{3}\right]$ is the residual soil water content, $\theta_{s}\left[\mathrm{~L}^{3} / \mathrm{L}^{3}\right]$ the saturated soil water content, $\alpha, n, m$ are empirical soil water retention factors defining the moisture retention characteristic's shape. $\theta_{r}, \theta_{s}, \alpha, n, m$ are considered as parameters, which have to be estimated from observed soil water retention data.

The hydraulic conductivity variation in the unsaturated profile can be expresed like a function of reduced soil water content $S_{e}$ and of the saturated hydraulic conductivity $K_{\mathrm{S}}$ :

$$
K=K_{s} S_{e}^{\mathrm{k}}\left[1-\left(1-S_{e}^{1 / m}\right)^{m}\right]^{2}
$$

Vereecken et al [4] estimated the moisture retention characteristics from simple soil properties as particle-size distribution (clay $\mathrm{Cl}(\%)$, and sand, $\mathrm{Sa}$ $(\%))$, dry bulk density, $B d\left(\mathrm{~g} \mathrm{~cm}^{-3}\right)$, and carbon content, $C(\%)$, using experimental data and suggested useful formulas for the parameters $\theta_{r}, \theta_{s}, \alpha, n$, $m$. 
For our experiment, during non-growing period, the evapotranspiration and plants water and nitrogen uptake have been neglected.

\subsection{Hydraulic model results}

The model's input parameters have been adjusted to obtain results which are relatively consistent with experimental conditions. The validity of the hydraulic model may be evaluated by comparing field measurements of soil volumetric water content to those predicted by the model.

For our experiment the soil composition was: $70 \% \mathrm{Sa}, 15 \% \mathrm{Cl}, 15 \%$ silt. The soil type is "loamy sand" according to the percentages chart (Belgian texture classes). For such a soil type, Vereeken et al [4] suggested the values: $\theta_{r}=0.09$, $\theta_{s}=0.41, \alpha=0.00742, n=1.21, m=1-1 / n$ (Mualem model). The saturated hydraulic conductivity, experimentaly obtained is: $K_{s}=2 \mathrm{~cm} /$ hour.

The simulation results, (fig. 4) show relatively good agreement between the computed values and the measured volumetric water content distribution, during a month, for a field experiment.
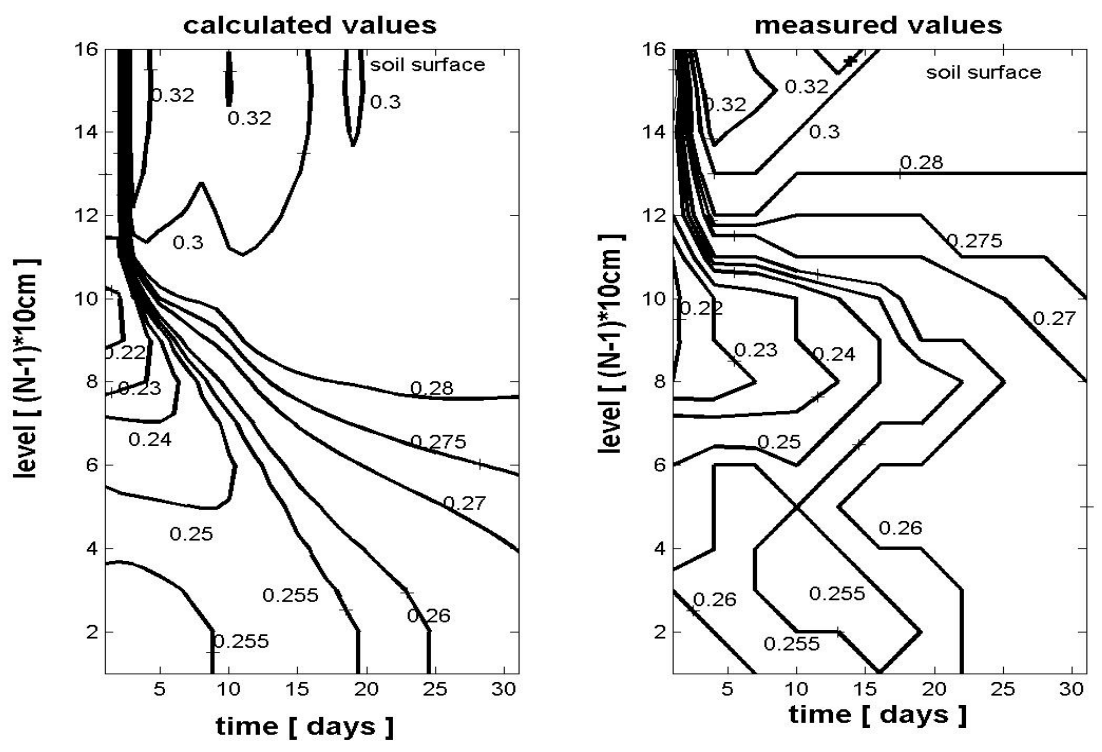

Figure 4: $\quad$ Measured and calculated values of volumetric water content distribution during a month, for a field experiment (contour lines $\theta$ $(z, t)=$ constant $)$.

For the rain intensity regime, used in the model calibration (fig. 6 a), the hydraulic quantities previously defined have been computed, and used like entrance data for the chemical model. In fig. 5 are presented the computed pressure head $h(z, t)$ and volumetric water content $\theta(z, t)$, profiles, during 24 
hours, in the third day of the first experiment (after 5 hours of rain). During 24 hours the influence of the infiltration attained $70 \mathrm{~cm}$ under the soil surface. The maximum values of pressure $h(z, t)$ and of umidity $\theta(z, t)$ have been after 5 hours of rain, in the first $10 \mathrm{~cm}$ layer of the soil. After 12 hours, the distance of infiltration influence increases and the surface values for $h$ and $\theta$ decrease.
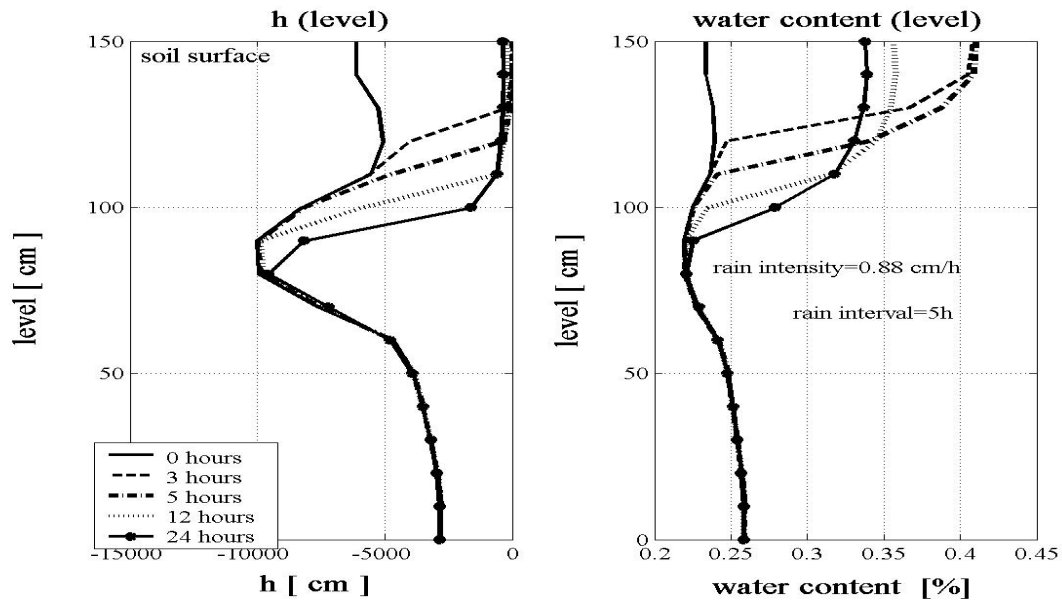

Figure 5: Computed pressure head $h(z, t)$ and volumetric water content $\theta(z, t)$, for the third day of the experiment depicted in fig. 6 a.

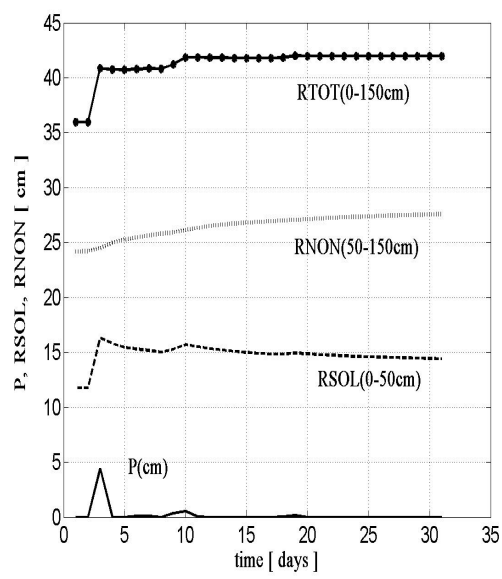

(a)

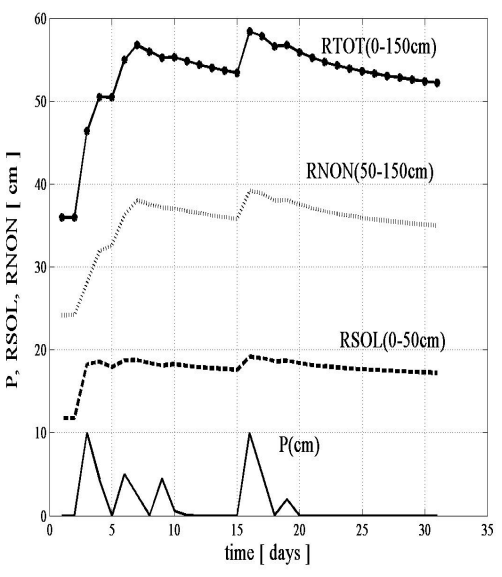

(b)

Figure 6: The rain intensity $\mathrm{P}(\mathrm{cm})$, and the water contents RSOL $(\mathrm{cm})$, RNON (cm), RTOT (cm), variation, for two experiments. 


\section{Hydraulic-chemical coupled model for nitrogen compounds transport in an unsaturated soil}

The hydraulic model gives the values of $h(z, t), \theta(z, t)$, QI, QIR, QE, QR, RSOL, RNON used in the biochemical nitrogen model (fig. 2).

The input data in the coupled model for nitrogen compounds transport, in an unsaturated soil are: rainfall intensity (P) (fig. 6a or 6b), soil hydraulic properties, and initial values for nitrogenous compounds, agricultural fertilizers concentration of nitrate (ANIT), ammonium (AAM) and organic nitrogen (AOR). The output data are: the water content (RSOL) in the roots region (0$50 \mathrm{~cm})$, the water content $(\mathrm{RNON})$ in the unsaturated without roots layer $(50 \mathrm{~cm}-$ $150 \mathrm{~cm}$ ), the evolution of each nitrogenous compounds in time (fig $7 \mathrm{a}$ or $7 \mathrm{~b}$ ). The concentrations in fig.7a correspond to (fig.6a) rain distribution, and the (fig. $7 b$ ) values, to (fig. 6b) rain regime.

The coupled model is applied to predict the nitrogen nitrate concentration at the upper boundary of the saturated layer (3) in fig. 3. This concentration is a boundary condition for the dispersion equation of the nitrogen-nitrate in the groundwater.

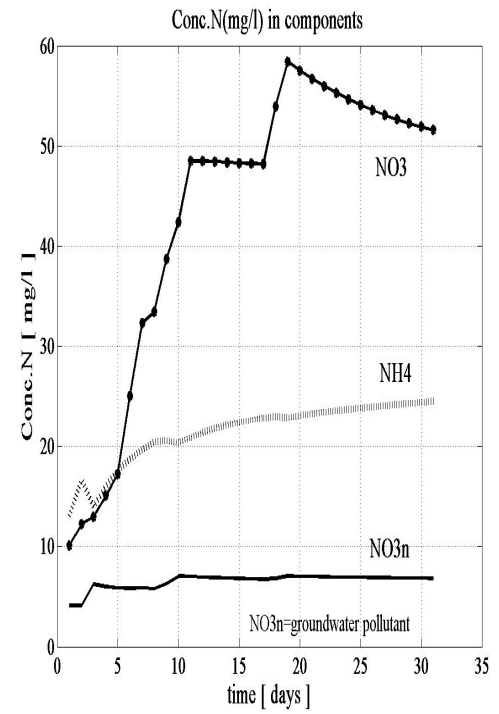

(a)

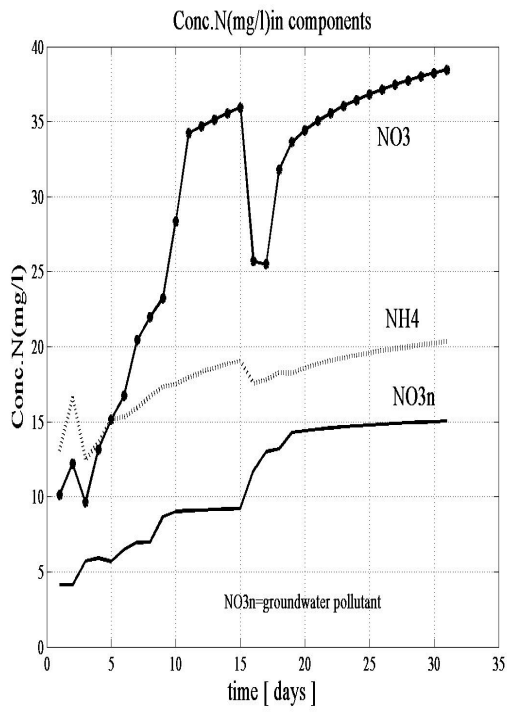

(b)

Figure 7: The coupled model sensitivity to rain intensity and its distribution.

\section{Conclusions}

The goal of our research has been to realise an useful coupled model for soil pollution prediction. 
The input data in the coupled model are: soil characteristics, hourly rain intensity during a month, and initial water content in the soil profile. The hydraulic model gives inputs for the biochemical model (QI/RSOL, QIR/RNON, QR/P). The other input data are the initial concentrations of nitrogen compounds $\left(\mathrm{N}^{-\mathrm{NO}_{3}}{ }^{-}\right)_{\text {init }}$, $(\mathrm{N}$ $\left.\mathrm{NH}_{4}{ }^{+}\right)_{\text {init }}$, (Norg) $)_{\text {init }}$, in the roots - unsaturated region and, $\left(\mathrm{N}-\mathrm{NO}_{3 \mathrm{n}}{ }^{-}\right)_{\text {init }}$ in the no-roots region. The rate values of chemical reactions, $\mathrm{k}_{\mathrm{am}}, \mathrm{k}_{\mathrm{ra}}, \mathrm{k}_{\mathrm{n}}, \mathrm{k}_{\mathrm{ad}}, \mathrm{k}_{\mathrm{rn}}$, have to be obtained by model calibration. For the moment we have used the values indicated in Geng [1] $\left(\mathrm{k}_{\mathrm{am}}=0.002, \mathrm{k}_{\mathrm{ra}}=0.1, \mathrm{k}_{\mathrm{ni}}=0.2, \mathrm{k}_{\mathrm{rn}}=0.1\right)$. The nitrogenous fertilizers $\left(\mathrm{kg} \mathrm{ha}^{-1}\right)$, on the soil surface, ANIT, AAM, AOR, can be done by agricultural plans, depending on the culture tip. Also the plants nitrogen uptake function, Fab, is known. The output data from the biochemical model are the concentrations of nitrogen compounds $(\mathrm{N}$ $\left.\mathrm{NO}_{3}{ }^{-}\right),\left(\mathrm{N}-\mathrm{NH}_{4}^{+}\right),(\mathrm{Norg})$, and $\left(\mathrm{N}-\mathrm{NO}_{3 \mathrm{n}}{ }^{-}\right)$, daily.

The hydraulic results are obtained considering a $\mathrm{d} t=0.25$ hour time step and a $\mathrm{d} z=1 \mathrm{~cm}$ space step. During a day, the model can compute the water content evolution $\theta(z, t)$ and the pressure head $h(z, t)$. The discharge values at any level can be computed, hourly or daily. So the internal hydraulic changes are very well described, each moment (fig. 5).

The rain intensity $(\mathrm{P})$ influences the hydraulic results and the nitrogen compounds concentrations (fig.7).

For a daily fertilizers input ANIT $=10\left(\mathrm{~kg} \mathrm{ha}^{-1}\right), \mathrm{AAM}=10\left(\mathrm{~kg} \mathrm{ha}^{-1}\right), \mathrm{AOR}=1(\mathrm{~kg}$ $\left.\mathrm{ha}^{-1}\right)$, and the initial values $\left(\mathrm{N}^{-N_{3}}{ }_{3}^{-}\right)_{\text {init }}=10\left(\mathrm{~kg} \mathrm{ha}^{-1}\right),\left(\mathrm{N}-\mathrm{NH}_{4}{ }^{+}\right)_{\text {init }}=10\left(\mathrm{~kg} \mathrm{ha}^{-1}\right)$, $(\text { Norg })_{\text {init }}=10\left(\mathrm{~kg} \mathrm{ha}^{-1}\right),\left(\mathrm{N}-\mathrm{NO}_{3 \mathrm{n}}{ }^{-}\right)_{\text {init }}=10\left(\mathrm{~kg} \mathrm{ha}^{-1}\right)$, we have considered two different hydraulic situations (fig. 6 a, fig. 6 b).

For a low rain intensity (fig. $6 \mathrm{a})$, the $\left(\mathrm{N}^{-\mathrm{NO}_{3}}{ }^{-}\right)$concentration increases during a month (fig. $7 \mathrm{a})$, and the $\left(\mathrm{N}-\mathrm{NO}_{3 \mathrm{n}}{ }^{-}\right)$values are relatively constant $(<10 \mathrm{mg} / \mathrm{l})$. For a monthly heavy rain (fig. 6b) the $\left(\mathrm{N}-\mathrm{NO}_{3}{ }^{-}\right)$values decrease and $\left(\mathrm{N}^{-} \mathrm{NO}_{3 \mathrm{n}}{ }^{-}\right)$ increases to $15 \mathrm{mg} / \mathrm{l}$ (fig. $7 \mathrm{~b}$ ).

We have considered a month at the beginning of plants growing.

The $\left(\mathrm{N}-\mathrm{NO}_{3 \mathrm{n}}{ }^{-}\right)$concentrations will be the time variable boundary condition for the two-dimensional dispersion equation in the groundwater flow, in a more general coupled model.

The work presented in this paper suggests that an hourly hydraulic model for the unsaturated soil behavior can give better input data for the chemical model, and so, better results of the coupled model.

The next steps in our research will be to introduce real data concerning the evapotranspiration, irrigations, and the fertilizers spreading, to calibrate the chemical model for an experiment, and to extend the model for 12 months.

\section{References}

[1] Geng, Q. Z., Modélisation conjointe du cycle de l'eau et du transfert des nitrates dans un système hydrologique, Thesis E N S M de Paris, 1988.

[2] Vauclin, M., Haverkamp, R., Vacman, G., Resolution numerique d'une ecuation de diffusion non lineaire, Presses Universitaires de Grenoble: Grenoble, pp. 161-170, 1979. 
[3] Van Genuchten, M.T., A closed form equation for predicting the hydraulic conductivity of unsaturated soils. Soil Sci. Soc. Am. J., 44, pp. 892-898, 1980.

[4] Vereecken, H., Manes, J., Feyen, J., Darius, P., Estimating the soil moisture retention characteristic from texture, bulk density and carbon content, Soil Science, vol. 148, No.6, pp. 389-402, 1989. 